\title{
Role of $s d h A$ and pfkA and catabolism of reduced carbon during colonization of cucumber roots by Enterobacter cloacae
}

\author{
Correspondence \\ Daniel P. Roberts \\ dan.roberts@ars.usda.gov
}

Received 27 December 2006

Revised 15 May 2007

Accepted 20 May 2007
Shengyi Liu, ${ }^{1}$ Xiaojia Hu, ${ }^{1}$ Scott M. Lohrke, ${ }^{2} \dagger$ C. Jaycn Baker, ${ }^{3}$ Jeffrey S. Buyer, ${ }^{2}$ Jorge T. de Souza ${ }^{4}$ and Daniel P. Roberts ${ }^{2}$

\author{
${ }^{1}$ Oil Crops Research Institute, Chinese Academy of Agricultural Sciences, Wuhan, People's \\ Republic of China \\ ${ }^{2}$ Sustainable Agricultural Systems Laboratory, USDA - Agricultural Research Service, Henry A. \\ Wallace Beltsville Agricultural Research Center, Beltsville, MD, USA \\ ${ }^{3}$ Molecular Plant Pathology Laboratory, USDA - Agricultural Research Service, Henry A. Wallace \\ Beltsville Agricultural Research Center, Beltsville, MD, USA \\ ${ }^{4}$ Universidade Federal do Recôncavo da Bahia, CCAAB, 44380-000 Cruz das Almas, BA, Brazil
}

We have been using a mutational approach to determine how plant-beneficial bacteria such as Enterobacter cloacae 501R3 obtain carbon and energy for colonization of subterranean portions of cucumber and other plants. Reduced carbon detected in cucumber root exudate consisted of 73.3 \% amino acids, $22.2 \%$ organic acids and $4.4 \%$ carbohydrate. Ent. cloacae M2, a mini-Tn5 $\mathrm{Km}$ transposon mutant of strain 501R3, was severely reduced in in vitro growth relative to strain $501 \mathrm{R} 3$ on the mixture of amino acids and organic acids detected in cucumber root exudate when these compounds were supplied as the sole source of carbon and energy, but was similar in growth on the mixture of carbohydrates detected in this exudate. Molecular and biochemical characterization of Ent. cloacae M2 indicated that the transposon was inserted in $s d h A$, which encodes a subunit of succinate dehydrogenase. Ent. cloacae A-11, a mutant of strain $501 \mathrm{R} 3$ with a mini-Tn5 $\mathrm{Km}$ insertion in $p f k A$, was severely reduced in in vitro growth relative to strain 501R3 on the mixture of carbohydrates detected in cucumber root exudate, but similar in growth on the mixture of amino acids and organic acids. When strains A-11 and M2 were coapplied with strain 501R3 to cucumber seeds above carrying capacity in competitive root colonization assays, populations of strains $A-11$ and $M 2$ were roughly one order of magnitude lower than those of strain 501R3 in cucumber rhizosphere, while populations of strains A-11 and M2 were similar to one other when coapplied to cucumber seeds. When Ent. cloacae strains were coapplied to cucumber seeds below carrying capacity, populations of $A-11$ and $M 2$ were roughly two to three orders of magnitude lower than those of 501R3 in cucumber rhizosphere, and populations of A11 were significantly lower than those of $\mathrm{M} 2$ when these two strains were coapplied to cucumber seed. The experiments reported here indicate an important role for $p f k A$ and $s d h A$ and the catabolism of carbohydrates, and of amino acids and organic acids, respectively, in the colonization of cucumber roots by Ent. cloacae. The results reported here also indicate that catabolism of carbohydrates by this bacterium is more important than catabolism of amino acids and organic acids at lower population densities, despite the much higher relative quantities of amino acids and organic acids detected in cucumber root exudate.
tPresent address: Geo-Centers, Inc., Naval Health Research Center, Environmental Health Effects Laboratory, Wright-Patterson Air Force Base, $\mathrm{OH}$, USA.

Abbreviations: Ap, ampicillin; Cam, chloramphenicol; Kan, kanamycin; Rif, rifampicin; SDH, succinate dehydrogenase; TCA cycle, tricarboxylic acid cycle.

The GenBank/EMBL/DDBJ accession number for the sequence of the translated proteins of Ent. cloacae is AY 194228.

\section{INTRODUCTION}

Applications of plant-beneficial bacteria as seed treatments for the suppression of plant diseases have been used to control root-infecting fungi, foliar pathogens, and soilborne plant-parasitic nematodes (Weller, 1988; Larkin et al., 1998; Meyer \& Roberts, 2002). Colonization of subterranean plant parts by these beneficial bacteria is 
thought to be essential for successful disease suppression in many applications (Lugtenberg et al., 2001). Chin-AWoeng et al. (2000) have provided compelling evidence that indicates a role for root colonization by Pseudomonas chlororaphis PCL1391 in suppression of Fusarium oxysporum f.sp. radicis-lycopersici on tomato. Others have also correlated colonization of plant surfaces with suppression of certain plant diseases (Bull et al., 1991). Traits important for colonization of plant surfaces by beneficial bacteria include chemotaxis, prototrophy, putrescine uptake and stress tolerance, and the production of antibiotics, $\mathrm{NADH}$ dehydrogenases, site-specific recombinase and certain bacterial surface molecules (Mazzola et al., 1992; Rainey, 1999; Lugtenberg et al., 2001; de Weert et al., 2002; Lohrke et al., 2002; Martínez-Granero et al., 2005).

Roots support growth and colonization by introduced beneficial bacteria and indigenous microbes through rhizodeposition (Lynch \& Whipps, 1990). Soluble carbon compounds within rhizodeposits, which can represent between 1 and $40 \%$ of total plant photosynthate (Whipps, 1990; Meharg, 1994), are thought to have the greatest stimulatory impact on growth and activity of microbes in the rhizosphere (Kraffczyk et al., 1984; Lynch \& Whipps, 1990), influencing regions of the soil that extend millimetre distances radially from the root (Helal \& Sauerbeck, 1983, 1986; Toal et al., 2000). Sugars, amino acids and organic acids are the dominant soluble reduced carbon compounds contained within the complex mixtures of nutrients released from roots (Lynch \& Whipps, 1990; Farrar et al., 2003). The availability of these compounds is thought to limit the growth of introduced beneficial bacteria. Most carbohydrates, amino acids and organic acids are extremely labile in the rhizosphere due to consumption by the indigenous microflora and resorption by roots (Jones \& Darrah, 1994b; Jones, 1998; Owen \& Jones, 2001). The release and availability of these compounds to microbes in the rhizosphere vary spatially along the root $(\mathrm{McD}$ Dougall \& Rovira, 1970; Chang \& Roberts, 1989; Jones \& Darrah, 1995; Jaeger et al., 1999; Bringhurst et al., 2001), with plant age, and with environmental conditions (Curl \& Truelove, 1986; Grayston et al., 1997).

Understanding the means by which introduced beneficial bacteria acquire the reduced carbon necessary for growth and colonization from the complex mixture of compounds released into the spermosphere and rhizosphere remains a challenge. In vitro techniques including the use of chemostats are available for the analysis of growth on low concentrations of mixtures of carbon compounds (Lendenmann et al., 1996; Kovarova-Kovar \& Egli, 1998). Methods for quantification of available reduced carbon components in rhizodeposits, and the dynamics of their release, are inadequate (Grayston et al., 1997; Jones, 1998; Jaeger et al., 1999), making representative in vitro studies of these compounds difficult. Consequently, spermosphere and rhizosphere colonization studies have been conducted with isogenic mutants of beneficial bacteria in which particular catabolic pathways have been made non-functional, allowing the importance of particular pathways and compounds in rhizodeposits to be evaluated (Roberts et al., 1999, 2000; Lugtenberg et al., 2001; Lohrke et al., 2002). Despite these studies, the contributing roles played by the catabolic pathways of beneficial bacteria, and the relative importance of carbohydrates, amino acids and organic acids within rhizodeposits to growth and colonization by beneficial bacteria, remain unclear (Roberts et al., 1999).

Enterobacter cloacae is an enteric, plant-beneficial bacterium that suppresses damping-off caused by Pythium ultimum on cucumber and other crops (Hadar et al., 1983; Nelson, 1988). Ent. cloacae colonizes the spermosphere and rhizosphere of several plant species, including cucumber (Roberts et al., 1999; Lohrke et al., 2002). Using strain A11, an isogenic mutant of Ent. cloacae 501R3, it has been shown that catabolism of carbohydrates by this bacterium is important for colonization of seeds that release limited quantities of reduced carbon. Strain A-11 contains a transposon insertion in $p f k A$, which encodes phosphofructose kinase A, a key enzyme in glycolysis (Roberts et al., 1999, 2000). M2 is a second prototrophic, transposon mutant of Ent. cloacae 501R3 that displays reduced colonization of seeds of cucumber and other crops (Roberts et al., 1996). We report here that strain M2 contains a mutation in $s d h A$, a gene encoding a subunit of the tricarboxylic acid (TCA) cycle enzyme succinate dehydrogenase $(\mathrm{SDH})$. The major objective of this study was to determine the relative importance of $p f k A$ and $s d h A$, and consequently the relative importance of catabolism of carbohydrate and of amino acids and organic acids, to the colonization of cucumber rhizosphere by Ent. cloacae after this bacterium had been introduced into the planting medium above and below carrying capacity.

Bacterial populations are thought to reach carrying capacity when resource availability reaches equilibrium with resource use by that population in a given environment (Wilson \& Lindow, 1994). Bacterial populations added above carrying capacity decline until the resources of the environment meet the resource needs of the population. In contrast, bacterial populations added below carrying capacity increase until carrying capacity is achieved. This equilibration of populations following the introduction of high and low numbers of bacteria has been observed in the spermosphere, rhizosphere and soil, and on leaf surfaces (Bennet \& Lynch, 1981; Crozat et al., 1982; Postma et al., 1990; Wilson \& Lindow, 1994; Roberts et al., 1997a). We performed experiments above and below carrying capacity, as the relative fitness of bacterial mutant strains has been shown to vary with the ability of the environment to meet the resource needs of the bacterial population (De Leij et al., 1998; Roberts et al., 1999).

\section{METHODS}

Bacterial strains and plasmids. A description of the bacterial strains and plasmids is given in Table 1. Ent. cloacae strains A-11 and M2 are prototrophic mutants of Ent. cloacae 501R3 containing single 
Table 1. Bacterial strains and plasmids

Abbreviations: $\mathrm{Ap}^{\mathrm{r}}$, ampicillin resistant; $\mathrm{Cam}^{\mathrm{r}}$, chloramphenicol resistant; $\mathrm{Kan}^{\mathrm{r}}$, kanamycin resistant; Rif ${ }^{\mathrm{r}}$, rifampicin resistant.

\begin{tabular}{|c|c|c|}
\hline Strain or plasmid & Relevant characteristics & Reference or source \\
\hline \multicolumn{3}{|l|}{ Strains } \\
\hline Ent. cloacae 501R3 & Spontaneous Rif ${ }^{\mathrm{r}}$ mutant of Ent. cloacae EcCT501 & Roberts et al. (1992) \\
\hline Ent. cloacae A-11 & Mini-Tn5 Km mutant of 501R3; pfkA:: mini-Tn5 Km; Rif ${ }^{\mathrm{r}}, \mathrm{Kan}^{\mathrm{r}}$ & Roberts et al. (1999) \\
\hline Ent. cloacae M2 & Mini-Tn5 Km mutant of 501R3; sdhA:: mini-Tn5 Km; Rif ${ }^{\mathrm{r}}, \mathrm{Kan}^{\mathrm{r}}$ & Roberts et al. (1996); this study \\
\hline E. coli $\mathrm{DH} 5 \alpha$ & 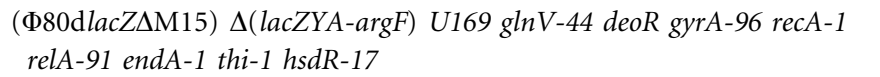 & Sambrook \& Russell (2001) \\
\hline \multicolumn{3}{|l|}{ Plasmids } \\
\hline pBeloBAC11 & $\mathrm{Cam}^{\mathrm{r}}$; cloning vector & New England BioLabs \\
\hline pGEM-7Zf $(+)$ & $\mathrm{Ap}^{\mathrm{r}}$; cloning vector & Promega \\
\hline pMK2 & $\begin{array}{l}\mathrm{Ap}^{\mathrm{r}}, \mathrm{Kan}^{\mathrm{r}} \text {; contains } 9.4 \mathrm{~kb} K p n \mathrm{I} \text { fragment from strain M2 containing } \\
s d h C D \text { mini-Tn } 5 \mathrm{Km}:: s d h A\end{array}$ & This study \\
\hline pMB7-1 & $\begin{array}{l}\mathrm{Ap}^{\mathrm{r}}, \mathrm{Kan}^{\mathrm{r}} \text {; contains } 6.3 \mathrm{~kb} B g l \mathrm{II} \text { fragment from strain M2 containing } \\
\text { mini-Tn } 5 \mathrm{Km}:: s d h A s d h B s u c A\end{array}$ & This study \\
\hline pGS133 & $\mathrm{Kan}^{\mathrm{r}}$; contains E. coli sdhCDAB & Wood et al. (1984) \\
\hline pBS4.5 & $\begin{array}{l}\text { Cam }{ }^{\mathrm{r}} \text {; contains } 4.5 \mathrm{~kb} \text { BamHI fragment from pGS133 in pBeloBAC11. } \\
\text { Contains E. coli sdhCDAB }\end{array}$ & This study \\
\hline
\end{tabular}

mini-Tn5 Km insertions (Roberts et al., 1996, 1999). Unless stated otherwise, strains were grown at $35{ }^{\circ} \mathrm{C}$ on Luria-Bertani (LB) broth (Miller, 1972) or agar, or M56 salts broth (Carlton \& Brown, 1981) or agar. Broth cultures were shaken at 250 r.p.m. Culture media were supplemented with $50 \mu \mathrm{g} \mathrm{ml}^{-1}$ ampicillin (Ap), $25 \mu \mathrm{g} \mathrm{ml}^{-1}$ chloramphenicol (Cam), $75 \mu \mathrm{g} \mathrm{ml}^{-1}$ kanamycin (Kan) or $100 \mu \mathrm{g} \mathrm{ml}^{-1}$ rifampicin (Rif), where appropriate.

Molecular techniques. DNA isolation, transformation, electroporation, restriction digests, electrophoresis, ligation and Southern blot hybridization were performed as described elsewhere (Sambrook \& Russell, 2001). Plasmid pMK2 was constructed by digesting Ent. cloacae M2 genomic DNA with $K p n \mathrm{I}$ followed by ligation to KpnIdigested pGEM-7Zf $(+)$. Plasmid pMB7-1 was constructed by digesting Ent. cloacae M2 genomic DNA with BglII followed by ligation to BglII-digested pGEM-7Zf $(+)$. Plasmids pMK2 and pMB71 were isolated after electroporation of these ligation mixtures into Escherichia coli $\mathrm{DH} 5 \alpha$ and selection on LB agar containing Ap and Kan. Plasmid pBS4.5 was constructed by digesting pGS133 with $B a m \mathrm{HI}$ and ligating the resulting $4.5 \mathrm{~kb} B a m \mathrm{HI}$ DNA fragment to pBeloBAC11 that had been digested with BamHI.

DNA sequencing was carried out by PCR-mediated Taq DyeDeoxy terminator cycle sequencing (Applied Biosystems). Sequences were analysed using the DNA analysis programs of DNASTAR (Lasergene). BLAST searches of databases (Altschul et al., 1997) were conducted with translated sequences by using the BLASTP program (National Center for Biotechnology Information; www.ncbi.nlm.nih.gov/ BLAST). Alignments between Ent. cloacae and E. coli DNA sequences were conducted with DNA sequence available at www.Ecocyc.org (Keseler et al., 2005). Pairwise identity and similarity of DNA and amino acid sequences were calculated with the BioEdit program version 7.0.5.3 (Hall, 1999). The PAM250 similarity matrix was adopted to calculate pairwise protein similarities.

SDH assay. Ent. cloacae strains were grown overnight in $250 \mathrm{ml}$ Erlenmeyer flasks containing $25 \mathrm{ml} \mathrm{LB}$ broth supplemented with appropriate antibiotics. Cells from overnight cultures were harvested by centrifugation, washed with ice-cold $30 \mathrm{mM}$ potassium phosphate, $\mathrm{pH} 7.6$, centrifuged again, and resuspended in ice-cold $30 \mathrm{mM}$ potassium phosphate, $\mathrm{pH} 7.6\left(0.25 \mathrm{~g}\right.$ cells $\left.\mathrm{ml}^{-1}\right)$. One millilitre cell suspension was sonicated (Vibra Cell sonicator with microtip, Sonics and Materials) six times for $10 \mathrm{~s}$ at a setting of 3.0. Cell debris was removed by centrifugation in a microcentrifuge at $4{ }^{\circ} \mathrm{C}$ for $1 \mathrm{~min}$. Supernatant was transferred to a clean microcentrifuge tube and centrifuged at $4{ }^{\circ} \mathrm{C}$ for $10 \mathrm{~min}$. This clarified supernatant was used for determinations of SDH activity and protein concentration. Reactions were performed at $22{ }^{\circ} \mathrm{C}$, and SDH activity was determined spectrophotometrically at $455 \mathrm{~nm}$ (Beckman DU 520 spectrophotometer, $1 \mathrm{~cm}$ path length, Beckman Coulter), as described by Veeger et al. (1969). In this determination, $1 \mathrm{~mol}$ succinate reduces $2 \mathrm{~mol}$ $\mathrm{K}_{3} \mathrm{Fe}(\mathrm{CN})_{6}$. Protein concentrations were determined by the method of Bradford (1976) with BSA as standard using procedures recommended by the manufacturer (Bio-Rad Laboratories). One unit of specific SDH activity was defined as a decrease of $0.01 A_{455}$ unit per minute per milligram protein. Experiments were performed twice with three replicates per treatment. The mean and SD of specific $\mathrm{SDH}$ activity were calculated for individual experiments.

Genetic restoration of growth on reduced carbon sources. Ent. cloacae strains 501R3, M2, M2(pBeloBAC11) and M2(pBS4.5) were streaked onto M56 salts agar plates containing $50 \mathrm{mM}$ acetate, citrate, succinate, glutamine, proline or serine, or no carbon source, and incubated at $35{ }^{\circ} \mathrm{C}$. The number of days of incubation required for formation of discrete colonies of each strain on each reduced carbon source was recorded. The experiment was performed at least twice with each reduced carbon source. Experiments were analysed independently.

Collection and characterization of cucumber root exudate. Cucumber (Cucumis sativum cv. Marketmore 76) root exudate was collected at 37 and 53 days from individual plants grown in $25 \mathrm{ml}$ sterile nutrient solution (Hoagland \& Arnon, 1950) in $250 \mathrm{ml}$ Erlenmeyer flasks at $22{ }^{\circ} \mathrm{C}$ in a growth chamber with a $12 \mathrm{~h}$ photoperiod. Seeds were surface-sterilized, as previously (Roberts et al., 1999), prior to use. Root exudate samples were checked for microbial contamination by spotting $10 \mu \mathrm{l}$ samples onto nutrient agar prior to analysis. Contaminated samples were discarded. Root exudate samples were passed through a $0.2 \mu \mathrm{m}$ pore-size filter and frozen until analysed.

Individual carbohydrates were determined by GC, essentially as previously (Sullivan \& Schewe, 1977; Roberts et al., 1997b), using an 
Table 2. Reduced carbon compounds detected in cucumber root exudate

Values are mean \pm SD of four replicate samples taken at 37 days and five replicate samples taken at 53 days. Means for individual carbohydrates, amino acids and organic acids at 37 and 53 days were not significantly different, so values from samples taken at these time points were combined prior to analysis. Note that two unidentified peaks eluted with retention times slightly different from those of ribose and certain disaccharides in root exudate samples.

\begin{tabular}{|c|c|}
\hline Compound & Concn ( $\mu$ g per plant) \\
\hline \multicolumn{2}{|l|}{ Carbohydrates } \\
\hline Arabinose & $1.0 \pm 2.5$ \\
\hline Cellibiose & $1.9 \pm 2.4$ \\
\hline Deoxyribose & $\mathrm{BDT} \dagger$ \\
\hline Fructose & $0.5 \pm 1.2$ \\
\hline Fucose & BDT \\
\hline Galactinol & BDT \\
\hline Galactose & $2.0 \pm 3.1$ \\
\hline Gentiobiose & $0.8 \pm 2.1$ \\
\hline Glucose & $5.2 \pm 2.7$ \\
\hline Isomaltose & $0.3 \pm 0.6$ \\
\hline Lactose & $0.5 \pm 1.1$ \\
\hline Maltose & $0.4 \pm 1.1$ \\
\hline Mannitol & $0.7 \pm 1.8$ \\
\hline Mannose & $1.1 \pm 2.7$ \\
\hline Raffinose & BDT \\
\hline Rhamnose & $2.4 \pm 3.8$ \\
\hline Ribose & BDT \\
\hline Sorbitol & BDT \\
\hline Sorbose & BDT \\
\hline Stachyose & BDT \\
\hline Sucrose & $11.8 \pm 11.4$ \\
\hline Trehalose & $0.8 \pm 1.9$ \\
\hline Xylose & $1.3 \pm 3.2$ \\
\hline \multicolumn{2}{|l|}{ Organic acids } \\
\hline Citrate & $12.7 \pm 1.1$ \\
\hline Isocitrate & $7.0 \pm 5.2$ \\
\hline$\alpha$-Ketoglutarate & $46.3 \pm 8.6$ \\
\hline Malate & $4.4 \pm 0.4$ \\
\hline Succinate & $83.4 \pm 17.5$ \\
\hline \multicolumn{2}{|l|}{ Amino acids ${ }^{\star}$} \\
\hline Alanine & BDT \\
\hline Arginine & $5.1 \pm 1.7$ \\
\hline Aspartate & $65.8 \pm 51.7$ \\
\hline Cysteine & BDT \\
\hline$\gamma$-Aminobutyrate & $0.9 \pm 2.5$ \\
\hline Glutamine & $13.0 \pm 2.5$ \\
\hline Glycine & $3.1 \pm 6.0$ \\
\hline Histidine & $15.1 \pm 18.4$ \\
\hline Homoserine & BDT \\
\hline Isoleucine & $25.3 \pm 27.3$ \\
\hline Leucine & $120.0 \pm 119.2$ \\
\hline Lysine & $2.8 \pm 0.3$ \\
\hline Methionine & $4.7 \pm 3.8$ \\
\hline Ornithine & $0.5 \pm 1.0$ \\
\hline Phenylalanine & $13.8 \pm 28.5$ \\
\hline Proline & $188.1 \pm 103.8$ \\
\hline Serine & $40.9 \pm 23.4$ \\
\hline
\end{tabular}

\begin{tabular}{|lc|}
\hline Compound & Concn ( $\boldsymbol{\mu g}$ per plant $)$ \\
\hline Threonine & $0.5 \pm 0.9$ \\
Tryptophan & $4.9 \pm 4.5$ \\
Tyrosine & $1.3 \pm 0.2$ \\
Valine & BDT \\
\hline
\end{tabular}

${ }^{\star}$ All amino acids reported here are the L stereoisomer. $\dagger$ BDT, Below detectable threshold.

Agilent 5890 gas chromatograph and 5970 mass selective detector fitted with an RTX-200 column [105 m long, $0.25 \mathrm{~mm}$ internal diameter (ID), $0.25 \mu \mathrm{m}$ film thickness; Restek]. Carbohydrates were detected by selective ion monitoring at $\mathrm{m} / z$ 69. Individual amino acids and organic acids were derivatized as described by MacKenzie (1987) and analysed by GC using an Agilent 6890 chromatograph. An Agilent Ultra 2 column ( $25 \mathrm{~m}$ long, $0.2 \mathrm{~mm} \mathrm{ID,} 200 \mu \mathrm{m}$ film thickness) was run at $1.0 \mathrm{ml} \mathrm{min}{ }^{-1}$ constant flow with hydrogen. Samples were injected at a split ratio of $100: 1$ and detected by electron capture. Samples were also run on an RTX-200 column (105 m long, $0.25 \mathrm{~mm}$ ID, $0.25 \mu \mathrm{m}$ film thickness; Restek) at $1.3 \mathrm{ml} \mathrm{min}{ }^{-1}$ constant flow with hydrogen, which gave better resolution of certain organic acids. Means for individual compounds at 37 and 53 days were not significantly different, so values from samples taken at 37 and 53 days were combined prior to analysis. Mean and SD were calculated from four replicate samples taken at 37 days and five replicate samples taken at 53 days for each compound.

In vitro growth assays. To determine growth on reduced carbon sources detected in exudate when supplied individually, Ent. cloacae strains cultured overnight in M56 salts broth plus $0.5 \%$ glycerol, v/v, were harvested by centrifugation, washed twice with M56 salts without a reduced carbon source, and resuspended to $\mathrm{OD}_{540} 1.00$ (Spectronic Instruments model Spectronic $20 \mathrm{D}^{+}$spectrophotometer, $1.8 \mathrm{~cm}$ light path) in M56 salts without a reduced carbon source, and $200 \mu \mathrm{l}$ of this suspension was used to inoculate $5 \mathrm{ml}$ M56 salts broth plus $50 \mathrm{mM}$ carbon source in $15 \mathrm{~cm} \times 1.8 \mathrm{~cm}$ diameter test tubes. Cultures were incubated at $35{ }^{\circ} \mathrm{C}$ and 100 r.p.m. If there was no growth after $48 \mathrm{~h}$ incubation, glucose was added to $0.5 \%$ final concentration and the culture incubated for an additional $8 \mathrm{~h}$ and tested for growth to ensure that the compound tested was not inhibitory. Growth of strains A-11 and M2 was considered substantially slower than that of strain 501R3 on a particular reduced carbon source if the $\mathrm{OD}_{540}$ was $60 \%$ or less than that of strain 501R3 at one or more time points. Growth by strains A-11 and M2 was considered slightly reduced if the $\mathrm{OD}_{540}$ was $61-95 \%$ that of strain $501 \mathrm{R} 3$ at one or more time points. Growth by strains M2 and A-11 was considered wild-type if the $\mathrm{OD}_{540}$ was at least $95 \%$ that of strain 501R3 at all time points. Experiments were performed at least twice with three replicate test tubes per strain for each test compound. Experiments were analysed independently.

Relative growth of Ent. cloacae strains was determined on synthetic cucumber root exudate (SRE-complete), or on the mixture of carbohydrates (SRE-CHO), or on the mixture of amino acids and organic acids (SRE-AA/OA) detected in cucumber root exudate. Experiments were performed as above, except that strains were incubated at $35{ }^{\circ} \mathrm{C}$ and 250 r.p.m. Carbohydrates, amino acids and organic acids detected in cucumber root exudate are listed in Table 2. For $0.5 \%$ SRE-complete medium, the following compounds were added to $1380 \mathrm{ml} \mathrm{M56}$ salts broth: $0.01 \mathrm{~g}$ L-arabinose, $0.019 \mathrm{~g}$ cellibiose, $0.005 \mathrm{~g}$ fructose, $0.02 \mathrm{~g}$ galactose, $0.008 \mathrm{~g}$ gentiobiose, $0.052 \mathrm{~g}$ glucose, $0.003 \mathrm{~g}$ isomaltose, $0.005 \mathrm{~g}$ lactose, $0.004 \mathrm{~g}$ maltose, 
$0.007 \mathrm{~g}$ mannitol, $0.011 \mathrm{~g}$ mannose, $0.024 \mathrm{~g}$ rhamnose, $0.118 \mathrm{~g}$ sucrose, $0.008 \mathrm{~g}$ trehalose, $0.013 \mathrm{~g}$ xylose, $0.051 \mathrm{~g}$ arginine, $0.658 \mathrm{~g}$ aspartate, $0.009 \mathrm{~g} \gamma$-aminobutyric acid, $0.13 \mathrm{~g}$ glutamine, $0.031 \mathrm{~g}$ glycine, $0.151 \mathrm{~g}$ histidine, $0.253 \mathrm{~g}$ isoleucine, $1.20 \mathrm{~g}$ leucine, $0.028 \mathrm{~g}$ lysine, $0.047 \mathrm{~g}$ methionine, $0.005 \mathrm{~g}$ ornithine, $0.138 \mathrm{~g}$ phenylalanine, $1.881 \mathrm{~g}$ proline, $0.409 \mathrm{~g}$ serine, $0.005 \mathrm{~g}$ threonine, $0.049 \mathrm{~g}$ tryptophan, $0.013 \mathrm{~g}$ tyrosine, $0.127 \mathrm{~g}$ citrate, $0.07 \mathrm{~g}$ isocitrate, $0.463 \mathrm{~g} \alpha-$ ketoglutarate, $0.044 \mathrm{~g}$ malate and $0.834 \mathrm{~g}$ succinate. For $0.5 \%$ SRE$\mathrm{CHO}$ medium, the carbohydrates, in the quantities listed above, were added to $61.4 \mathrm{ml} \mathrm{M56}$ salts broth. For $0.5 \%$ SRE-AA/OA medium, the amino acids and organic acids, in the quantities listed above, were added to $1316 \mathrm{ml} \mathrm{M} 56$ salts broth. Other concentrations of these media were prepared by diluting the $0.5 \%$ media with M56 salts broth. All media were filter-sterilized prior to use. Growth on these media was determined by measuring $\mathrm{OD}_{540}$ periodically. Experiments were performed at least twice with each medium with three replicates per treatment. Experiments were analysed independently.

Root colonization assays. Ent. cloacae strains were grown overnight in LB broth, washed in sterile distilled water (SDW), and diluted in SDW to obtain the desired population density. Suspensions $(40 \mu \mathrm{l})$ containing strains 501R3, A-11, M2, 501R3+A-11, $501 \mathrm{R} 3+\mathrm{M} 2$ or A-11 + M2 were applied to cucumber seeds. Seeds were sown (one seed per pot) in potting mix (Redi-Earth Peat Lite Mix, Scott's Horticultural Products) in $6.5 \mathrm{~cm}$ diameter $\times 25 \mathrm{~cm}$ deep pots and incubated in a growth chamber at $22{ }^{\circ} \mathrm{C}$ with a $12 \mathrm{~h}$ photoperiod. Plants were watered from above as needed throughout the experiment. At sampling time, the entire root system and tightly adhering planting medium were placed in SDW, sonicated for 5 min (model 8210, Branson Ultrasonics) and c.f.u. for each strain per root system determined by dilution plating. c.f.u. for strain 501R3 was determined by plating on M56 salts agar plus $0.2 \% \mathrm{~N}$-acetylglucosamine plus Rif, or $0.2 \%$ proline plus Rif, c.f.u. for strain A-11 was determined by plating on M56 salts agar plus $0.2 \%$ proline plus Rif and Kan, while c.f.u. for strain M2 was determined by plating on M56 salts agar plus $0.2 \% \mathrm{~N}$-acetylglucosamine plus Rif and Kan. Strain 501R3 cannot grow in the presence of Kan, while strains A-11 and M2 cannot grow with $\mathrm{N}$-acetylglucosamine and proline as the source of reduced carbon, respectively. Mean $\log _{10}$ (c.f.u.) per root system was determined and compared using Least-squares Means in proc GLM (SAS Institute). Experiments were performed twice at each initial population level with six replicates per treatment and analysed independently $(n=6)$.

\section{RESULTS}

\section{Molecular and biochemical characterization of Ent. cloacae M2}

Ent. cloacae M2 was selected for further study after previous experiments had demonstrated this strain to be reduced in cucumber seedling colonization and to be significantly impaired in growth on amino acids (Roberts et al., 1996). Southern hybridization analysis had also demonstrated the presence of a single mini-Tn5 Km insertion in the chromosome of strain M2 (Roberts et al., 1996). Sequencing outward from mini-Tn5 $\mathrm{Km}$ in plasmids pMK2 and pMB7-1 (Table 1, Fig. 1), using primers specific for the ends of mini-Tn $5 \mathrm{Km}$, indicated that this transposon was inserted in a region of the strain M2 genome with a high degree of similarity to $s d h A$, which encodes the flavoprotein subunit of SDH. Analysis of the combined DNA sequences from the Ent. cloacae portions of pMK2 and pMB7-1 revealed five ORFs with high similarity to $s d h C D A B$ and sucA (Fig. 1). Each of the four ORFs for $s d h C D A B$ contained a predicted ATG start codon and TAA stop codon, and was sufficient to encode polypeptides of $159,115,572$ and 238 amino acids, respectively. sdhCDAB collectively encode all subunits of SDH (Keseler et al., 2005). A partial sequence of sucA was obtained that contained all but the terminal nine amino acid codons of this gene. $s d h C D A B$ and $s u c A$ have an identical organization and direction of transcription in Ent. cloacae and $E$. coli K12 (Keseler et al., 2005). Comparison of this 6771 bp sequence from Ent. cloacae with that from E. coli K12 indicated an overall $84.9 \%$ DNA sequence identity.

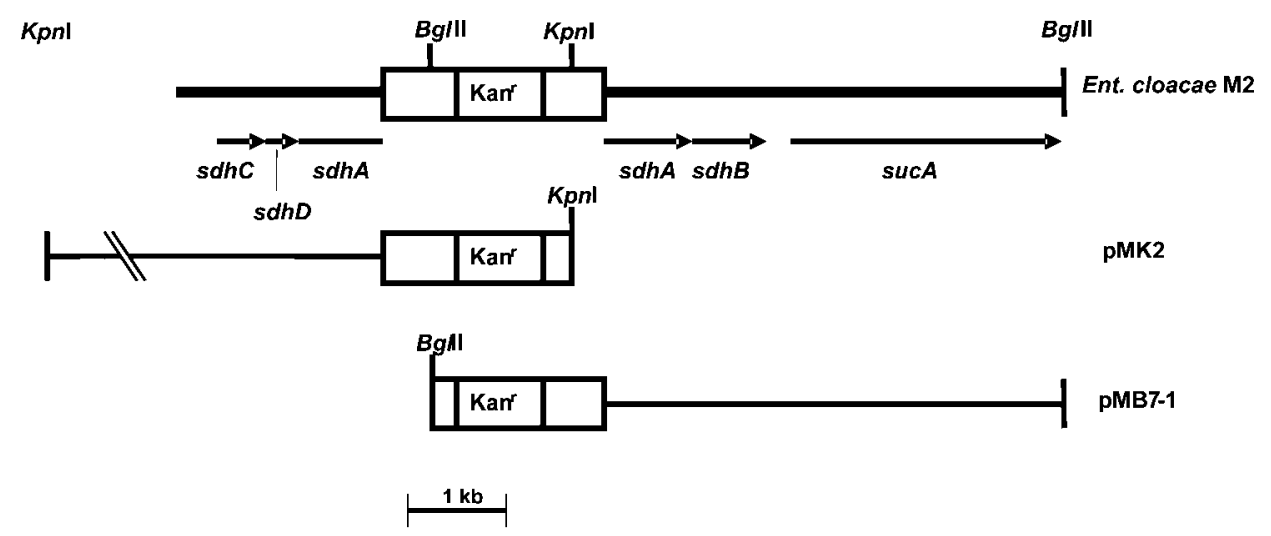

Fig. 1. Physical maps of the portion of the Ent. cloacae M2 genome containing mini-Tn5 Km, and of plasmids pMK2 and pMB7-1. The location of genes and direction of transcription are indicated by horizontal arrows. The box indicates the site of the mini-Tn5 Km insertion. Kan r, location of gene encoding Kan resistance; Bg/ll and Kpnl, cleavage sites for restriction endonucleases $B g / l$ and $K p n l$, respectively. sdhCDAB encode $\mathrm{SDH}$ subunits $\mathrm{CDAB}$, respectively. sucA encodes oxoglutarate dehydrogenase subunit $A$. Features are approximately to scale. 
To confirm that the mini-Tn $5 \mathrm{Km}$ insertion in $s d h A$ in strain M2 affected SDH activity, an enzymic assay was performed. Specific SDH activity in cell lysates from Ent. cloacae M2 was $0.24 \pm 0.01$ units, approximately $30 \%$ of the SDH activity in lysates from the parental strain 501R3. Specific SDH activity in cell lysates from Ent. cloacae 501R3 was $0.77 \pm 0.02$ units. Introduction of pBS4.5, containing sdhCDAB from E. coli, into strain M2 resulted in a 6.1-fold increase in SDH activity relative to strain M2. Cell lysates from M2(pBS4.5) had $1.47 \pm 0.02$ units of specific SDH activity. Strain M2 containing the empty cloning vector pBeloBAC1 1 had $0.23 \pm 0.02$ units SDH activity, equivalent to that of strain M2 alone. Results from a second experiment were similar (data not shown). It is possible that the SDH background activity in the $s d h A$ mutant M2 is due to fumarate reductase. Many enteric bacteria contain both SDH and fumarate reductase, and fumarate reductase can catalyse succinate oxidation as measured with the $\mathrm{K}_{3} \mathrm{Fe}(\mathrm{CN})_{6}$ method used in this study (Hirsch et al., 1963; Cecchini et al., 2002). Fumarate reductase is typically produced in enteric bacteria at low oxygen tensions (Jones \& Gunsalus, 1985).

Strain M2 did not grow on agar plates containing M56 salts plus $50 \mathrm{mM}$ acetate, succinate, glutamine, proline or serine. All of these reduced carbon compounds supported growth by strain 501R3. Strain M2 was reduced in growth relative to $501 \mathrm{R} 3$ on M56 salts agar plus $50 \mathrm{mM}$ citrate. As with strain M2, sdh mutants of E. coli were deficient in growth on acetate and succinate (Herbert \& Guest, 1971). The growth capabilities of E. coli sdh mutants on citrate and the amino acids glutamine, proline and serine have not been reported (Herbert \& Guest, 1971). The introduction of $E$. coli sdhCDAB on pBS4.5 into M2 completely restored growth relative to strain 501R3 on citrate, succinate and proline, and increased growth on acetate, glutamine and serine relative to strain M2. Plasmid pBeloBAC11, the cloning vector, did not result in increased growth by strain M2 on any compound tested. None of the strains grew on M56 salts agar without a source of reduced carbon. Results from a second experiment were similar (data not shown).

\section{Analysis of cucumber root exudate}

The complex mixture of reduced carbon compounds detected in cucumber root exudate contained substantially more amino acids and organic acids than carbohydrate (Table 2). Amino acids, organic acids and carbohydrates formed 73.3, 22.2 and $4.4 \%$, respectively, of the reduced carbon. Although variable between replicates, substantial amounts of the amino acids aspartate, leucine, proline and serine were detected, forming 9.5, 17.4, 27.2 and $5.9 \%$ of the total reduced carbon, respectively. Substantial amounts of the organic acids succinate and $\alpha$-ketoglutarate were also present, forming 12.1 and $6.7 \%$ of the total reduced carbon detected, respectively. Glucose and sucrose were the most prominent carbohydrates released from cucumber roots. It is possible that the quantities of organic acids relative to those of sugars and amino acids in root exudates were overestimated for the following reasons. (1) Plant roots in nutrient solution have been shown to resorb over $90 \%$ of the sugar-carbon previously released into the nutrient solution (Jones \& Darrah, 1993), and proteinaceous amino acids have been shown to be resorbed by roots via active transport (Jones \& Darrah, 1994a). (2) No active uptake mechanism has been shown to occur in roots for organic acids, and organic acids can be preferentially released under certain environmental conditions (Jones, 1998).

\section{In vitro growth by Ent. cloacae strains on compounds detected in cucumber root exudate}

The relative growth was determined of Ent. cloacae strain M2 on reduced carbon compounds detected in cucumber exudate at concentrations greater than $1 \mu \mathrm{g}$ per plant (Table 2) and which also supported growth by strain 501R3. The amino acids aspartate, glutamine, proline and serine; the organic acids citrate, malate and succinate; and the carbohydrates arabinose, cellibiose, galactose, glucose, mannose, rhamnose, sucrose and xylose were supplied individually in M56 salts broth at $50 \mathrm{mM}$ final concentration. Strain M2, containing a mutation in $s d h A$, was substantially slower in growth relative to strain 501R3 on all amino acids and organic acids tested, and slightly slower in growth on carbohydrates when these compounds were supplied individually (data not shown). Consistent with this, strain M2 was substantially reduced in growth relative to strain 501R3 on the mixture of all amino acids and organic acids detected in cucumber root exudate (SRE-AA/ OA medium) when this mixture was supplied at 0.5 (Fig. 2a), 0.1, 0.05 and $0.01 \%$ (data not shown). It should be noted that significant growth by strain M2 was achieved by $23 \mathrm{~h}$ in these experiments on SRE-AA/OA medium (data not shown). Growth on the mixture of all carbohydrates detected in cucumber root exudate (SRECHO medium) by strains M2 and 501R3 was similar when this mixture was supplied at 0.5 (Fig. 2b), 0.1, 0.05 and $0.01 \%$ (data not shown). Similar results were obtained in repeated experiments (data not shown).

Strain A-11, containing a mutation in $p f k A$, was substantially slower in growth relative to strain 501R3 on all carbohydrates tested, with the exception of rhamnose, but essentially unaffected in growth on amino acids and organic acids when these compounds were supplied individually (data not shown). Consistent with this, strain A-11 was substantially reduced in growth relative to strain 501R3 on the mixture of all carbohydrates detected in cucumber root exudate (SRE-CHO medium) when this mixture was supplied at 0.5 (Fig. 2b), 0.1, 0.05 and $0.01 \%$ (data not shown). It should be noted that significant growth by strain A-11 was achieved by $23 \mathrm{~h}$ in these experiments on SRE-CHO medium (data not shown). Growth by strains A-11 and 501R3 on the mixture of all amino acids and organic acids detected in cucumber root 

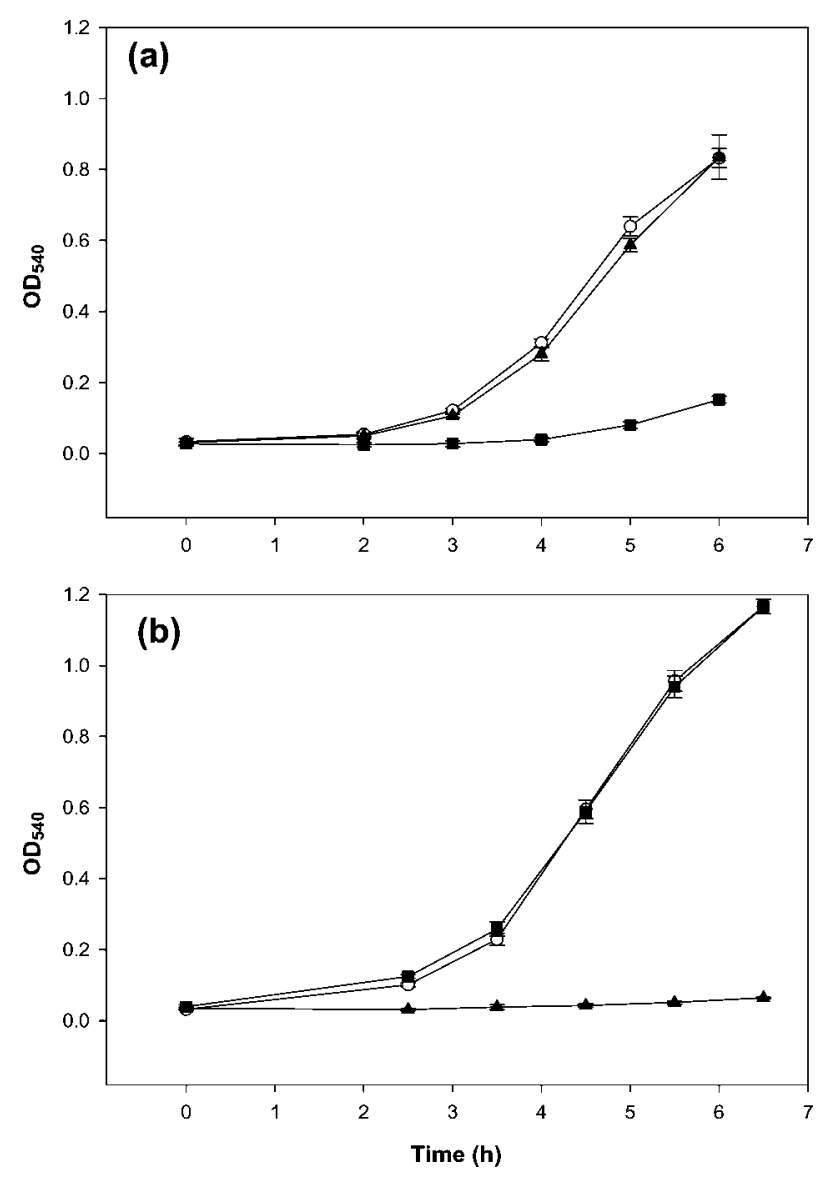

Fig. 2. Growth of Ent. cloacae strains $501 \mathrm{R} 3, \mathrm{~A}-11$ and $\mathrm{M} 2$ on (a) $0.5 \%$ SRE-AA/OA and (b) $0.5 \%$ SRE-CHO media. The complete lists of reduced carbon components in each of these media are described in Methods. (O) Strain 501R3; $(\boldsymbol{\Delta})$ strain A-11; ( $\boldsymbol{\square})$ strain $M 2$. The mean $\pm S D \quad O D_{540}$ over time from a single experiment is shown. Treatments were replicated three times.

exudate (SRE-AA/OA medium) was similar when this mixture was supplied at 0.5 (Fig. 2a), 0.1, 0.05 and $0.01 \%$ (data not shown). Similar results were obtained in repeated experiments (data not shown).

Growth by strains 501R3, M2 and A-11 was also compared on SRE-complete medium, which represented the relative individual levels of all carbohydrates, amino acids and organic acids detected in cucumber root exudate (Table 2). The carbohydrate in SRE-complete medium had a considerable influence on the growth of Ent. cloacae, despite the low relative quantity of carbohydrate in the medium. Conversely, the amino acids and organic acids in the SRE-complete medium had little influence on the growth of Ent. cloacae, despite the high relative quantity of these compounds in the medium. Ent. cloacae A-11, which had wild-type growth on the mixture of amino acids and organic acids in SRE-complete medium (Fig. 2a), and failed to grow over approximately $6 \mathrm{~h}$ on the mixture of carbohydrate in this medium (Fig. 2b), failed to increase significantly in optical density over $\sim 6 \mathrm{~h}$ in SRE-complete medium at $0.5,0.1$ and $0.05 \%$ (Fig. 3), despite the availability for growth of relatively large quantities of amino acids and organic acids in this medium. In contrast, wild-type strain 501R3 achieved significant growth relative to strain A-11 over this time period on $0.5,0.1$ and $0.05 \%$ SRE-complete medium (Fig. 3). Ent. cloacae M2, which had wild-type growth on the mixture of carbohydrates in SREcomplete medium (Fig. 2b) and failed to grow over approximately $6 \mathrm{~h}$ on the mixture of amino acids and organic acids in this medium (Fig. 2a), grew at essentially wild-type rates for the initial 3.5, 2.5 and $2.5 \mathrm{~h}$ when this medium was supplied at concentrations of $0.5,0.1$ and $0.05 \%$, respectively (Fig. 3), despite the availability of only small quantities of carbohydrates for growth. After these times, growth by strain M2 relative to strain 501R3 slowed, presumably due to depletion of the carbohydrate in the SRE-complete medium. Only on $0.01 \%$ SRE-complete medium was the growth rate of strain A-11 greater than that of M2 and similar to that of strain 501R3 (Fig. 3d). The total concentration of carbohydrate in $0.01 \%$ SREcomplete medium was only $0.00044 \%$, too low a concentration of reduced carbon to support growth by Ent. cloacae. Similar results were obtained in repeated experiments (data not shown).

The relative impact of carbohydrates and of amino acids and organic acids in synthetic cucumber root exudate was further tested in experiments in which strain 501R3 was grown concurrently on $0.5,0.1,0.05$ and $0.01 \%$ SREcomplete, SRE-CHO and SRE-AA/OA media (Fig. 4). In all experiments, strain 501R3 grew more rapidly on SRE-CHO medium than on SRE-AA/OA medium at a given concentration. In addition, with increasing dilution of the three media, growth by strain 501R3 on SRE-complete medium became less like that of strain 501R3 on SRE-CHO medium and more like that of strain 501R3 on SRE-AA/ OA medium (Fig. 4). Presumably this was due to the dilution of the carbohydrate mixture portion of the SREcomplete medium, which supports rapid growth by Ent. cloacae, to levels too low to support growth. Similar results were obtained in repeated experiments (data not shown). It should be noted that synthetic cucumber root exudate was used rather than 'authentic' exudate from cucumber roots in these in vitro experiments to ensure the consistency of the component reduced carbon compounds available for growth in repeated experiments. Individual reduced carbon compounds within an exudate can vary from sample to sample (Table 2; D. P. Roberts and J. S. Buyer, unpublished results).

\section{In situ growth on reduced carbon in cucumber rhizosphere by strains of Ent. cloacae}

Strain M2, which was diminished in growth on the amino acids and organic acids in cucumber root exudate, and strain A-11, which was diminished in growth on the carbohydrates, were both significantly reduced in competitive 

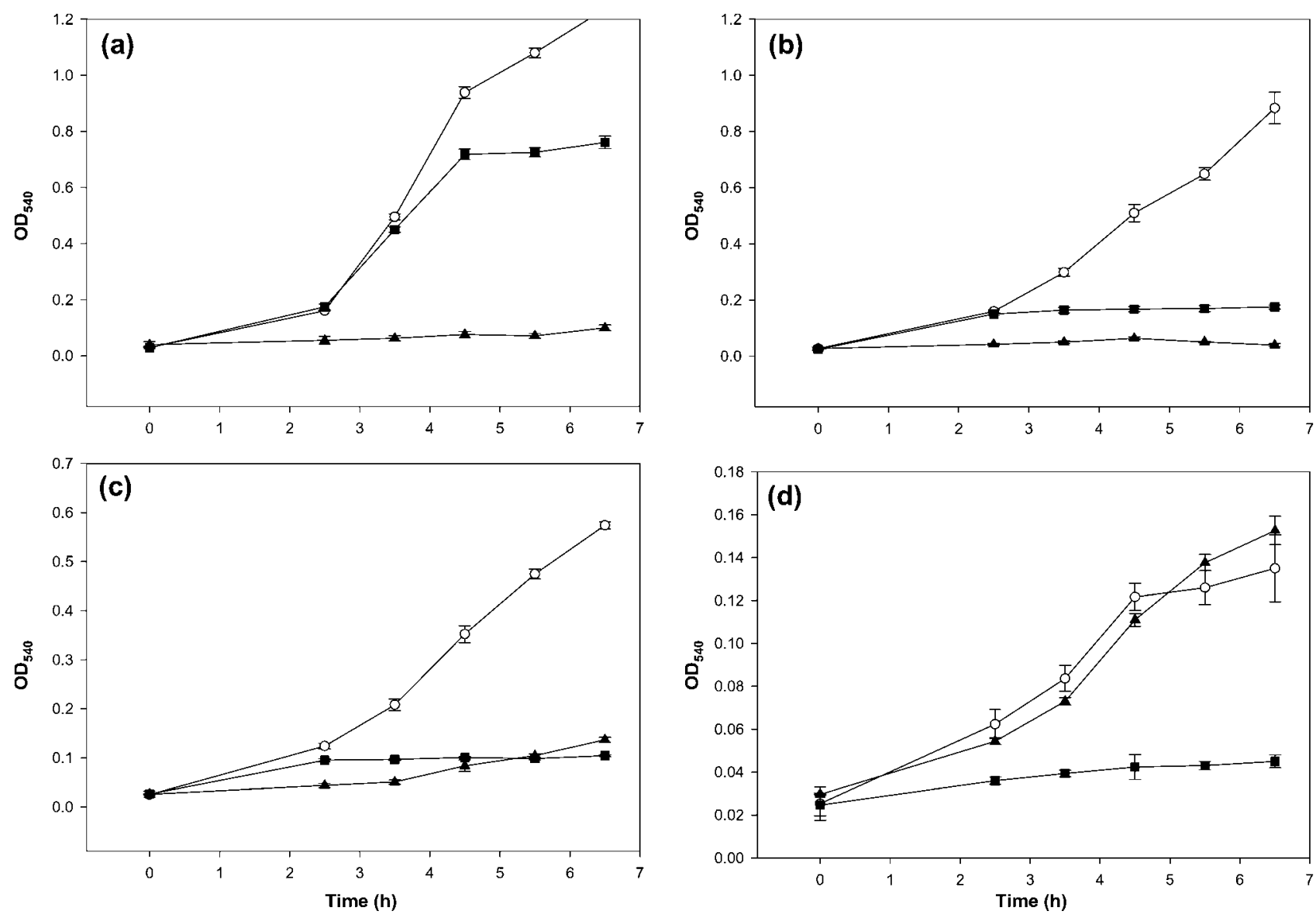

Fig. 3. Growth of Ent. cloacae strains 501R3, A-11 and M2 on SRE-complete media supplied at (a) $0.5 \%$, (b) $0.1 \%$, (c) $0.05 \%$ and (d) $0.01 \%$. The complete list of reduced carbon components in this medium is described in Methods. ( $\bigcirc)$ Strain 501R3; $(\boldsymbol{\Delta})$ strain $A-11 ;(\boldsymbol{\square})$ strain M2. The mean \pm SD OD $_{540}$ over time from a single experiment is shown. Treatments were replicated three times. The $y$-axis scale varies from panel to panel.

cucumber root colonization relative to wild-type strain 501R3 when the strains were coapplied with strain 501R3 to cucumber seeds (Tables 3 and 4). Additionally, the impact of the lost nutritional capabilities on cucumber root colonization by Ent. cloacae was greatest when Ent. cloacae was applied to cucumber seed at lower population densities (slightly below carrying capacity). Populations of strains A-11 and M2 were 76- to 7943-fold lower than those of strain 501R3 when strains A-11 and M2 were coincubated with strain 501R3 in cucumber rhizosphere during competitive cucumber root colonization experiments performed at low population densities in potting mix (Table 3). Wild-type strain 501R3 typically increased in population around fivefold over the course of these experiments, in which $\sim 4.5 \log _{10}$ (c.f.u.) per seed of each bacterial strain was coapplied. Similar results were obtained in a second experiment (data not shown). Populations of strains M2 and A-11 were significantly different $(P \leqslant 0.018)$ but only three- to 37 -fold lower than those of 501R3 when these strains were coapplied to cucumber seed above carrying capacity in experiments conducted in potting mix (Table 4). Wild-type strain 501R3 decreased in population around 10-fold over the course of these experiments, in which $\sim 7.8 \log _{10}$ (c.f.u.) per seed of each bacterial strain was coapplied. Similar results were obtained in a second experiment (data not shown).

Results from experiments in which low populations $[\sim 3.5$ $\log _{10}$ (c.f.u.) per seed] of strains M2 and 501R3 were applied individually to cucumber seeds in potting mix were consistent with those of the competitive root colonization experiments that were performed at slightly below carrying capacity. Populations of strain M2 ranged from similar to 255-fold lower than those of strain 501R3 in two experiments, and were significantly lower than those of 501R3 $(P \leqslant 0.004)$ at one time point in both 55-day experiments (data not shown). In equivalent experiments, populations of strain A-11 ranged from similar to 2190fold lower than those of strain 501R3, and were significantly different $(P \leqslant 0.05)$ at three of four time points in two 55-day experiments (data not shown). Root 

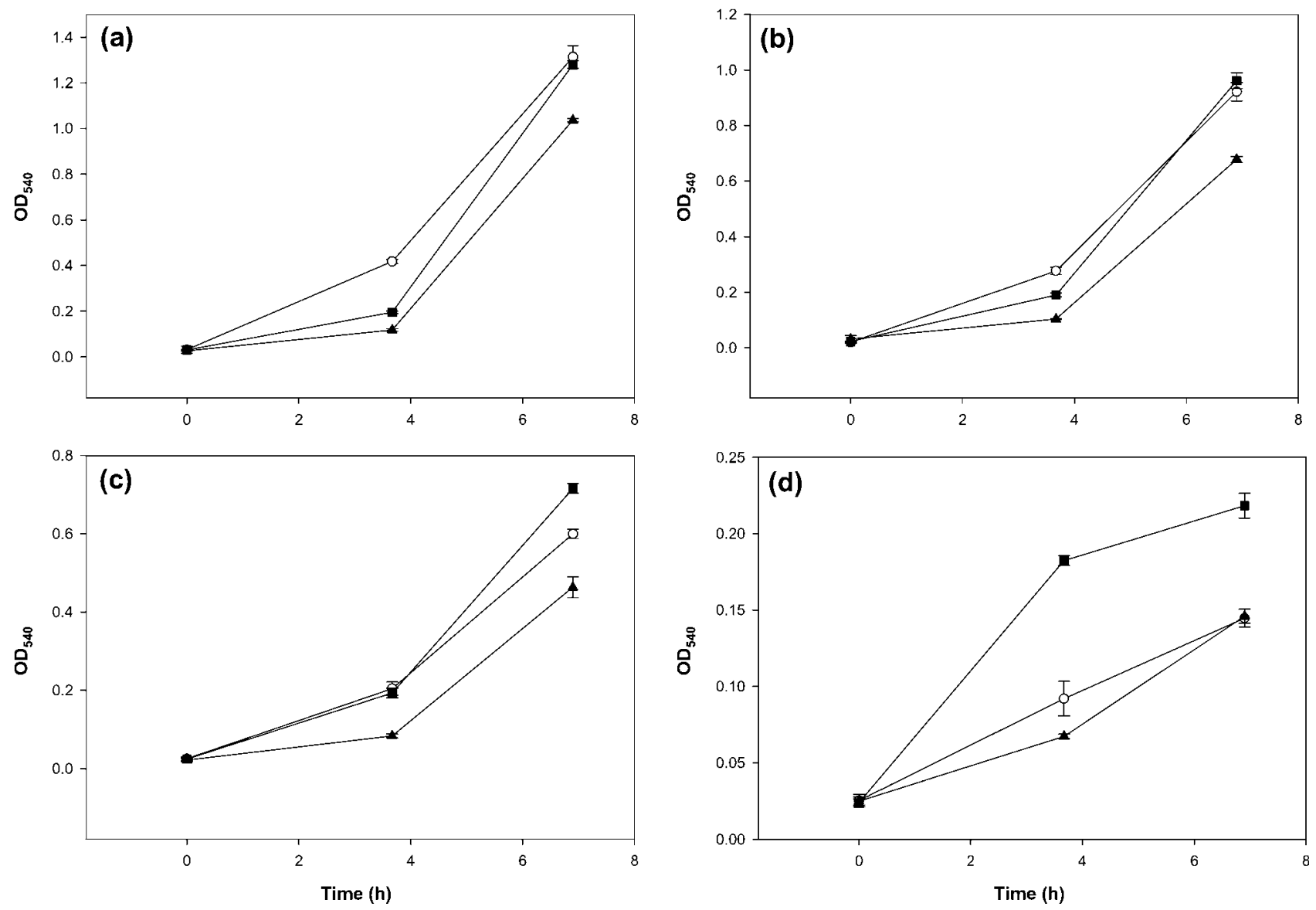

Fig. 4. Growth of Ent. cloacae strain $501 \mathrm{R} 3$ on SRE-complete $(\bigcirc)$, SRE-AA/OA $(\mathbf{\Delta})$ and SRE-CHO ( $\boldsymbol{\square}$ ) media supplied at (a) $0.5 \%$, (b) $0.1 \%$, (c) $0.05 \%$ and (d) $0.01 \%$. The complete lists of reduced carbon components in these media are described in Methods. The mean \pm SD $\mathrm{OD}_{540}$ over time from a single experiment is shown. Treatments were replicated three times. The $y$-axis scale varies from panel to panel.

colonization experiments in which strains M2, A-11 and 501R3 were applied individually to cucumber seeds at populations above carrying capacity $\left[\sim 7.5 \log _{10}\right.$ (c.f.u.) per seed] were also consistent with the competitive root colonization experiments (data not shown). Populations of strain M2 ranged from two- to fivefold lower $(P>0.05$ at all time points) than those of strain 501R3 in three of six experiments, while populations of strain $\mathrm{M} 2$ ranged from five- to 110 -fold lower than those of strain 501R3 $(P \leqslant 0.05$ at all time points) in the other three experiments. Likewise, populations of strain A-11 ranged from similar to sixfold lower ( $P>0.05$ at all time points) than those of strain $501 \mathrm{R} 3$ in three of four experiments, and ranged from sixto 19 -fold lower than those of strain 501R3 $(P \leqslant 0.05$ at all time points) in the other experiment.

Consistent with the in vitro growth experiments with the SRE media, the impact of the loss of carbohydrates as nutrients was greater than that of the loss of amino acids and organic acids on colonization by Ent. cloacae in competitive cucumber root colonization experiments when
A-11 and M2 were coapplied to cucumber seeds at lower population densities (Table 3 ). In experiments in which strains A-11 and M2 were coapplied to seeds at low population densities, populations of strain A-11 were 41to $>3000$-fold lower than those of strain M2 at all time points. In contrast, strains A-11 and M2 were equally competitive in cucumber rhizosphere when the two strains were coapplied to cucumber seeds at populations above carrying capacity (Table 4). Similar results were obtained in repeated experiments (data not shown).

\section{DISCUSSION}

To date, three major pathways that function in carbon metabolism have been shown to be important for colonization of cucumber roots by Ent. cloacae. Experiments reported here clearly demonstrate roles for the Embden-Meyerhof-Parnas pathway and the TCA cycle in colonization. Ent. cloacae mutants A-11 and M2 were both reduced in colonization of cucumber roots (Tables 3 
Table 3. Competitive colonization of cucumber rhizosphere by Ent. cloacae strains when applied below carrying capacity

Approximately $4.5 \log _{10}$ (c.f.u.) per seed of each strain was applied. Plants were grown in deep pots filled with potting mix. Results of a single experiment are shown.

\begin{tabular}{|c|c|c|c|c|c|}
\hline \multirow[t]{2}{*}{ Day } & \multicolumn{3}{|c|}{$\underline{\left.\log _{10} \text { (c.f.u. }\right)^{\star}}$} & \multirow[t]{2}{*}{$\operatorname{Pr}>\mathbf{T} \dagger$} & \multirow{2}{*}{$\begin{array}{l}\text { Population } \\
\text { difference } \ddagger\end{array}$} \\
\hline & 501R3 & M2 & A-11 & & \\
\hline \multicolumn{6}{|c|}{ 501R3 vs M2 } \\
\hline 13 & 4.48 & 2.60 & $\mathrm{ND} \S$ & 0.017 & 76-fold \\
\hline 28 & 4.53 & 1.20 & ND & $<0.0001$ & 2138-fold \\
\hline 41 & 4.89 & 1.91 & ND & 0.0002 & 955-fold \\
\hline 55 & 4.32 & 1.79 & ND & 0.0016 & 339-fold \\
\hline \multicolumn{6}{|c|}{$501 R 3$ vs $\mathrm{A}-11$} \\
\hline 13 & 4.63 & $\mathrm{ND}$ & 1.70 & $<0.0001$ & 851-fold \\
\hline 28 & 4.78 & $\mathrm{ND}$ & 1.80 & $<0.0001$ & 955 -fold \\
\hline 41 & 4.27 & $\mathrm{ND}$ & BDTll & $<0.0001$ & $\mathrm{NC}$ \\
\hline 55 & 5.22 & $\mathrm{ND}$ & 1.32 & $<0.0001$ & 7943-fold \\
\hline \multicolumn{6}{|c|}{ M2 vs A-11 } \\
\hline 13 & $\mathrm{ND}$ & 3.43 & 0.60 & 0.0007 & 676-fold \\
\hline 28 & $\mathrm{ND}$ & 3.67 & 0.70 & 0.0004 & 933-fold \\
\hline 41 & $\mathrm{ND}$ & 4.13 & BDT & $<0.0001$ & NC \\
\hline 55 & $\mathrm{ND}$ & 2.24 & 0.63 & 0.0499 & 41-fold \\
\hline
\end{tabular}

${ }^{*} \log _{10}$ (c.f.u.) was determined by dilution-plating onto media selective for each strain. Values are the mean of six replicates and expressed as mean $\log _{10}$ (c.f.u.) per root system.

$\dagger \operatorname{Pr}>\mathrm{T}$ difference in $\log _{10}$ (c.f.u.) per root system between strains in this row.

$\ddagger$ Difference in population sizes between paired strains at that particular sampling time.

$\S N D$, Not determined.

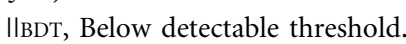

$\mathbf{S}_{\mathrm{NC}}$, Not calculated. Value could not be calculated.

and 4). Genetic and biochemical restoration of colonization by A-11 (Roberts et al., 1999) strongly suggests that the reduction in colonization by this strain in experiments reported here was solely due to insertional inactivation of $p f k A$, a key enzyme in the glycolytic Embden-MeyerhofParnas pathway in enteric bacteria. Genetic and biochemical data presented here indicate that the defect in colonization by strain M2 was the result of insertional inactivation of the locus that contains $s d h A$ and consequently the disruption of the TCA cycle. SDH functions in the TCA cycle, catalysing the oxidation of succinate to fumarate with the concurrent reduction of ubiquinone in the cell membrane under aerobic conditions. In E. coli, $s d h C D A B, s u c A B$ and $s u c C D$ form a locus with transcription initiation and regulation primarily at the upstream $s d h C$ promoter (Cunningham \& Guest, 1998; Park et al., 1997). A weak sucA promoter also initiates transcription of sucAB and sucCD (Park et al., 1997). In addition to sdhCDAB and sucA having the same physical orientation in Ent. cloacae and E. coli, regulatory regions of the Ent.
Table 4. Competitive colonization of cucumber rhizosphere by Ent. cloacae strains when applied above carrying capacity

Approximately $7.8 \log _{10}$ (c.f.u.) per seed of each strain was applied. Plants were grown in deep pots filled with potting mix. Results of a single experiment are shown.

\begin{tabular}{|c|c|c|c|c|c|}
\hline \multirow[t]{2}{*}{ Day } & \multicolumn{3}{|c|}{$\underline{\left.\log _{10} \text { (c.f.u.) }\right)^{*}}$} & \multirow[t]{2}{*}{$\mathbf{P r}>\mathbf{T} \dagger$} & \multirow{2}{*}{$\begin{array}{l}\text { Population } \\
\text { difference }\end{array}$} \\
\hline & $501 \mathrm{R} 3$ & M2 & A-11 & & \\
\hline \multicolumn{6}{|c|}{ 501R3 vs M2 } \\
\hline 11 & 6.20 & 5.71 & ND\$ & 0.018 & Threefold \\
\hline 26 & 6.04 & 5.05 & ND & $<0.0001$ & 10 -fold \\
\hline 40 & 6.18 & 5.07 & $\mathrm{ND}$ & $<0.0001$ & 13-fold \\
\hline 53 & 6.61 & 5.30 & ND & $<0.0001$ & 20 -fold \\
\hline \multicolumn{6}{|c|}{$501 R 3$ vs A-11 } \\
\hline 11 & 6.44 & ND & 5.77 & 0.0065 & Fivefold \\
\hline 26 & 6.07 & $\mathrm{ND}$ & 4.75 & $<0.0001$ & 20 -fold \\
\hline 40 & 6.15 & $\mathrm{ND}$ & 4.80 & $<0.0001$ & 22 -fold \\
\hline 53 & 6.39 & $\mathrm{ND}$ & 4.82 & $<0.0001$ & 37 -fold \\
\hline \multicolumn{6}{|c|}{ M2 vs A-11 } \\
\hline 11 & ND & 5.93 & 6.01 & 0.75 & 1.2-fold \\
\hline 26 & ND & 5.47 & 5.20 & 0.27 & Twofold \\
\hline 40 & ND & 5.61 & 5.67 & 0.85 & Same \\
\hline 53 & ND & 5.67 & 5.87 & 0.42 & 1.6-fold \\
\hline
\end{tabular}

${ }^{\star} \log _{10}$ (c.f.u.) was determined by dilution-plating onto media selective for each strain. Values are the mean of six replicates and expressed as mean $\log _{10}$ (c.f.u.) per root system.

$\dagger \operatorname{Pr}>\mathrm{T}$ difference in $\log _{10}$ (c.f.u.) per root system between strains in this row.

‡Difference in population sizes between paired strains at that particular sampling time.

$\S \mathrm{ND}$, Not determined.

cloacae sdhCDABsucA cluster share significant homology with those of E. coli. ArcA, cAMP-CRP and Fur binding sites with high DNA sequence identity to those of E. coli have been identified (Lynch \& Lin, 1996; Shen \& Gunsalus, 1997; Zhang et al., 2005). In light of these similarities, the data reported here correlate $s d h A$, and possibly the sdhCDABsucABsucCD locus, with colonization of cucumber roots. However, sucCD and $s u c A B$ encode succinyl coenzyme A synthetase and subunits of the $\alpha$-oxoglutarate dehydrogenase complex (Keseler et al., 2005), respectively, which, like SDH, function in the TCA cycle. A previous study has demonstrated a role for the pentose phosphate pathway, the third major pathway for carbon metabolism in enteric bacteria, in cucumber root colonization by Ent. cloacae (Lohrke et al., 2002).

The impact of the mutations in $s d h A$ in strain M2 and in $p f k A$ in strain A-11 on cucumber root colonization by Ent. cloacae was due to the role of these genes in deriving energy for growth and other cellular functions from reduced carbon in cucumber root exudate, and was not due to indirect effects. Although SDH functions in the TCA cycle and the TCA cycle is an important source of intermediates 
for cellular biosynthesis (Guest \& Russell, 1992), the mutation in $s d h A$ did not impact cucumber root colonization due to the creation of auxotrophic requirements for growth, as M2 and other sdh mutants are prototrophs (Herbert \& Guest, 1971; Roberts et al., 1996). As with strain M2, the mutation in $p f k A$ in A-11 did not create auxotrophic requirements for growth, as A-11 and other pfkA mutants are prototrophs (Roehl \& Vinopal, 1976; Roberts et al., 1992). There are also no reports of SDH or phosphofructose kinase A, the $p f k A$ gene product, functioning as global regulators. Phosphofructose kinase A is an allosteric enzyme that sets the pace of glycolysis (Fraenkel, 1996), and as such functions primarily in regulating the catabolism of carbohydrate. Finally, metabolic flux analyses of mutants containing individual mutations in central metabolic pathways have shown that increased flux to alternative pathways can occur with indirect effects on growth (Canonaco et al., 2001; Emmerling et al., 2002). However, this does not appear to be the case for strains $\mathrm{M} 2$ and A-11, as both strains exhibited wild-type growth in vitro on certain substrates (Fig. 2) and in the spermospheres of certain seeds (Roberts et al., 1996, 1999).

The competitive cucumber root colonization assays presented here revealed that the loci containing $s d h A$ and $p f k A$ were more important for colonization when bacteria were applied at populations slightly below carrying capacity than when applied at populations above carrying capacity (Tables 3 and 4). In these experiments, strain combinations were coapplied to cucumber seeds at two population levels that differed by three orders of magnitude. Differences in populations between 501R3 and A-11 and between 501R3 and M2 were much greater in competitive colonization experiments in which the strains were coapplied to cucumber seed at lower population densities. In addition, differences in populations between strains A-11 and M2 were only detected when the lower population densities of these strains were coapplied to cucumber seed. Certain environments, such as those associated with plant surfaces, are characteristically limiting to micro-organisms in one or more nutrients (Andrews, 1992; Harder \& Dijkhuizen, 1983; Paulitz, 1990; Sørensen et al., 2001). Gene expression studies have documented the importance of genes involved in carbon and energy metabolism and in the uptake of reduced carbon compounds under carbon-limiting conditions (Hua et al., 2004). It is not known why the importance of $p f k A$ and $s d h A$, and consequently the importance of carbohydrates, amino acids and organic acids, to colonization by Ent. cloacae varied with population density on cucumber roots. However, if $p f k A$ and $s d h A$ were simply important under carbon-limiting conditions, then one would expect the impact of these mutations to be greatest at the higher population densities, at which approximately three orders of magnitude more Ent. cloacae cells were competing for available resources then at lower population densities. A more probable explanation is that multiple resources were limiting at the higher population levels tested, while only carbon was limiting to growth at the lower population level. Multiple-nutrient-limited growth has been well documented in the literature (Egli \& Zinn, 2003). In chemostat studies that analyse competition between microbes, in which there is more than one growth-limiting nutrient, co-existence of the competitors is more likely to occur (Gottschal, 1993). This hypothesis awaits further experimentation.

The in vitro (Figs 3 and 4) and in situ (Tables 3 and 4) experiments reported here demonstrated a substantial role for carbohydrates as nutrients for growth during colonization of cucumber roots by Ent. cloacae, even when these carbohydrates were not available in significant quantities. The relationship between growth rate and fitness/competitiveness may explain why carbohydrate played such a substantial role in competitive root colonization. Carbohydrate supported the most rapid growth by Ent. cloacae, while amino acids and organic acids supported slower growth rates (Fig. 4; Roberts et al., 2000). Rapid growth by microbes is thought to lead to increased fitness (Harder \& Dijkhuizen, 1983; Koch, 2001).

Our studies clearly indicate a role for carbohydrate catabolism by Ent. cloacae in colonization of cucumber rhizosphere, in contrast to earlier published root colonization work with plant-beneficial pseudomonads (Lugtenberg et al., 1999, 2001). Those authors found that a mutant with a transposon insertion in $z w f$, which encodes a key enzyme in the glycolytic Entner-Doudoroff pathway, was unaffected in competitive colonization of tomato roots. Based on work with a mutant containing a mutation just upstream of the $m d h$ operon, they suggest that organic acids are the most important for colonization of tomato rhizosphere by pseudomonads. It is possible that these differences are due to differences in experimental design: the use of non-sterile planting media and cucumber plants in our studies as opposed to the use of sterile planting media and tomato plants in the work by Lugtenberg and co-workers. However, it is more likely that these differences are due to differing catabolic strategies between enteric bacteria, such as Ent. cloacae, and pseudomonads. Enteric bacteria have been shown to have a functional EntnerDoudoroff pathway, but the preferred catabolic route for carbohydrates in these bacteria is via the EmbdenMeyerhof-Parnas pathway. The primary function of the Entner-Doudoroff pathway in enteric bacteria is thought to be in sugar acid metabolism (Peekhaus \& Conway, 1998). Enteric bacteria, such as Ent. cloacae, clearly prefer carbohydrates to organic acids and amino acids as sources of carbon and energy, as evidenced by rapid growth on carbohydrates relative to organic acids and amino acids (Roberts et al., 1992, 2000), and cAMP-CRP-mediated repression, in the presence of sugars, of enzymes that function in organic acid and amino acid catabolism (Botsford \& Harman, 1992). The reverse is true for pseudomonads, in which growth rates are higher on certain organic acids (Collier et al., 1996). Additionally, certain TCA cycle intermediates have been shown to 
repress expression of the hex regulon and the glucose transporter, both of which function in the catabolism of carbohydrates by pseudomonads (Collier et al., 1996). The work presented here, together with earlier work (Lugtenberg et al., 1999, 2001), suggests that nutritional preferences for carbon and energy, and the importance of these nutrients, during colonization of plant roots by beneficial bacteria vary with the bacterial species.

\section{ACKNOWLEDGEMENTS}

We are grateful to Laurie McKenna, Norton Mock, Ricky Brathwaite and David Lee for excellent technical assistance. We thank Dr John Guest, University of Sheffield, for the generous gift of plasmid pGS133.

\section{REFERENCES}

Altschul, S. F., Madden, T. L., Schaffer, A. A., Zhang, J., Miller, W. \& Lipman, D. J. (1997). Gapped BLAST and PSI-BLAST: a new generation of protein database search programs. Nucleic Acids Res 25, 3389-3402.

Andrews, J. H. (1992). Biological control in the phyllosphere. Annu Rev Phytopathol 30, 603-635.

Bennet, R. A. \& Lynch, J. M. (1981). Colonization potential of bacteria in the rhizosphere. Curr Microbiol 6, 137-138.

Botsford, J. L. \& Harman, J. G. (1992). Cyclic AMP in prokaryotes. Microbiol Rev 56, 100-122.

Bradford, M. M. (1976). A rapid and sensitive method for the quantitation of milligram quantities of protein utilizing the principle of protein-dye binding. Anal Biochem 72, 248-254.

Bringhurst, R. M., Cardon, Z. G. \& Gage, D. J. (2001). Galactosides in the rhizosphere: utilization by Sinorhizobium meliloti and development of a biosensor. Proc Natl Acad Sci U S A 98, 4540-4545.

Bull, C. T., Weller, D. M. \& Thomashow, L. S. (1991). Relationship between root colonization and suppression of Gaeumannomyces graminis var. tritici by Pseudomonas fluorescens 2-79. Phytopathology 81, 954-959.

Canonaco, F., Hess, T. A., Heri, S., Wang, T., Szyperski, T. \& Sauer, U. (2001). Metabolic flux response to phosphoglucose isomerase knockout in Escherichia coli and impact of overexpression of the soluble transhydrogenase UdhA. FEMS Microbiol Lett 204, 247-252.

Carlton, B. C. \& Brown, B. J. (1981). Gene Mutation. In Manual of Methods for General Bacteriology, pp. 222-242. Edited by P. Gerhardt, R. G. E. Murray, R. N. Costilow, E. W. Nester, W. A. Wood, N. R. Krieg \& G. B. Phillips. Washington, DC: American Society for Microbiology.

Cecchini, G., Schroeder, I., Gunsalus, R. P. \& Macklashina, E. (2002). Succinate dehydrogenase and fumarate reductase from Escherichia coli. Biochim Biophys Acta 1553, 140-157.

Chang, K. J. \& Roberts, J. K. M. (1989). Observation of cytoplasmic and vacuolar malate in maize root tips by ${ }^{13} \mathrm{C}-\mathrm{NMR}$ spectroscopy. Plant Physiol 89, 197-203.

Chin-A-Woeng, T. F. C., Bloemberg, G. V., Mulders, I. H. M., Dekkers, L. C. \& Lugtenberg, B. J. J. (2000). Root colonization by phenazine-1carboxamide-producing bacterium Pseudomonas chlororaphis PCL1391 is essential for biocontrol of tomato foot and root rot. Mol Plant Microbe Interact 13, 1340-1345.

Collier, D. N., Hagar, P. W. \& Phibbs, P. V., Jr (1996). Catabolite repression control in the pseudomonads. Res Microbiol 147, 551-561.
Crozat, Y., Cleyet-Marel, J. C., Giraud, J. J. \& Obaton, M. (1982). Survival rates of Rhizobium japonicum populations introduced into different soils. Soil Biol Biochem 14, 401-405.

Cunningham, L. \& Guest, J. R. (1998). Transcription and transcript processing in the $s d h C D A B-s u c A B C D$ operon of Escherichia coli. Microbiology 144, 2113-2123.

Curl, E. A. \& Truelove, B. (1986). The Rhizosphere. New York: Springer-Verlag.

De Leij, F. A. A. M., Thomas, C. E., Bailey, M. J., Whipps, J. M. \& Lynch, J. M. (1998). Effect of insertion site and metabolic load on the environmental fitness of a genetically modified Pseudomonas fluorescens isolate. Appl Environ Microbiol 64, 2634-2638.

de Weert, S., Vermeiren, H., Mulders, I. H. M., Kuiper, I., Hendrickx, N., Bloemberg, G. V., Vanderleyden, J., De Mot, R. \& Lugtenberg, B. J. J. (2002). Flagella-driven chemotaxis towards exudate components is an important trait for tomato root colonization by Pseudomonas fluorescens. Mol Plant Microbe Interact 15, 1173-1180.

Egli, T. \& Zinn, M. (2003). The concept of multiple-nutrient-limited growth of microorganisms and its application in biotechnological processes. Biotechnol Adv 22, 35-43.

Emmerling, M., Dauner, M., Ponti, A., Fiaux, J., Hochuli, M., Szyperski, T., Wüthrich, K., Bailey, J. E. \& Sauer, U. (2002). Metabolic flux responses to pyruvate kinase knockout in Escherichia coli. J Bacteriol 184, 152-164.

Farrar, J., Hawes, M., Jones, D. \& Lindow, S. (2003). How roots control the flux of carbon to the rhizosphere. Ecology 84, 827-837.

Fraenkel, D. G. (1996). Glycolysis. In Escherichia coli and Salmonella. Cellular and Molecular Biology, pp. 189-198. Edited by F. C. Neidhardt, R. Curtis III, J. L. Ingraham, E. C. C. Lin, K. B. Low, B. Magasanik, W. S. Reznikoff, M. Riley, M. Schaechter \& H. E. Umbarger. Washington, DC: American Society for Microbiology.

Gottschal, J. C. (1993). Growth kinetics and competition - some contemporary comments. Antonie van Leeuwenhoek 63, 299-313.

Grayston, S. J., Vaughan, D. \& Jones, D. (1997). Rhizosphere carbon flow in trees, in comparison with annual plants: the importance of root exudation and its impact on microbial activity and nutrient availability. Appl Soil Ecol 5, 29-56.

Guest, J. R. \& Russell, G. C. (1992). Complexes and complexities of the citric acid cycle in Escherichia coli. Curr Top Cell Regul 33, 231-247.

Hadar, Y., Harman, G. E., Taylor, A. G. \& Horton, J. M. (1983). Effects of pregermination of pea and cucumber seeds and of seed treatment with Enterobacter cloacae on rots caused by Pythium spp. Phytopathology 73, 1322-1325.

Hall, T. A. (1999). BioEdit: a user-friendly biological sequence alignment editor and analysis program for Windows 95/98/NT. Nucleic Acids Symp Ser 41, 95-98.

Harder, W. \& Dijkhuizen, L. (1983). Physiological responses to nutrient limitation. Annu Rev Microbiol 37, 1-23.

Helal, H. M. \& Sauerbeck, D. (1986). Effect of plant roots on carbon metabolism of soil microbial biomass. Z Pflanzenernaehr Bodenkd 149, 181-188.

Herbert, A. A. \& Guest, J. R. (1971). Two mutations affecting utilization of $\mathrm{C}_{4}$-dicarboxylic acids by Escherichia coli. J Gen Microbiol 63, 151-162.

Hirsch, C. A., Rasminsky, M., Davis, B. D. \& Lin, E. C. C. (1963). A fumarate reductase in Escherichia coli distinct from succinate dehydrogenase. J Biol Chem 238, 3770-3774.

Hoagland, D. R. \& Arnon, D. I. (1950). The Water-Culture Method for Growing Plants without Soil. Circular no. 347. Berkeley, CA: University of California Agricultural Experiment Station. 
Hua, Q., Yang, C., Oshima, T., Mori, H. \& Shimizu, K. (2004). Analysis of gene expression in Escherichia coli in response to changes of growth-limiting nutrient in chemostat cultures. Appl Environ Microbiol 70, 2354-2366.

Jaeger, C. H., III, Lindow, S. E., Miller, W., Clark, E. \& Firestone, M. K. (1999). Mapping of sugar and amino acid availability in soil around roots with bacterial sensors of sucrose and tryptophan. Appl Environ Microbiol 65, 2685-2690.

Jones, D. L. (1998). Organic acids in the rhizosphere - a critical review. Plant Soil 205, 25-44.

Jones, D. L. \& Darrah, P. R. (1993). Re-sorption of organic compounds by roots of Zea mays L. and its consequences in the rhizosphere. II. Experimental and model evidence for simultaneous exudation and resorption of soluble C compounds. Plant Soil 153, 47-57.

Jones, D. L. \& Darrah, P. R. (1994a). Amino-acid influx at the soilroot interface of Zea mays L. and its implications in the rhizosphere. Plant Soil 163, 1-12.

Jones, D. L. \& Darrah, P. R. (1994b). Role of root derived organicacids in the mobilization of nutrients from the rhizosphere. Plant Soil 166, 247-257.

Jones, D. L. \& Darrah, P. R. (1995). Influx and efflux of organic-acids across the soil-root interface of Zea mays $\mathrm{L}$. and its implications in the rhizosphere C flow. Plant Soil 173, 103-109.

Jones, H. M. \& Gunsalus, R. P. (1985). Transcription of Escherichia coli fumarate reductase genes ( $f r d A B C D)$ and their coordinate regulation by oxygen, nitrate, and fumarate. J Bacteriol 164, 1100-1109.

Keseler, I. M., Collado-Vides, J., Gama-Castro, S., Ingraham, J., Paley, S., Paulsen, I. T., Peralta-Gil, M. \& Karp, P. D. (2005). EcoCyc: a comprehensive database resource for Escherichia coli. Nucleic Acids Res 33, D334-D337.

Koch, A. L. (2001). Oligotrophs versus copiotrophs. Bioessays 23, 657-661.

Kovarova-Kovar, K. \& Egli, T. (1998). Growth kinetics of suspended microbial cells: from single-substrate-controlled growth to mixedsubstrate kinetics. Microbiol Mol Biol Rev 62, 646-666.

Kraffczyk, I., Trolldeiner, G. \& Beringer, H. (1984). Soluble root exudates of maize: influence of potassium supply and rhizosphere microorganisms. Soil Biol Biochem 16, 315-322.

Larkin, R. P., Roberts, D. P. \& Gracia-Garza, J. A. (1998). Biological control of fungal diseases. In Fungicidal Activity. Chemical and Biological Approaches to Plant Protection, pp. 149-191. Edited by D. Hutson \& J. Miyamoto. New York: Wiley.

Lendenmann, U., Snozzi, M. \& Egli, T. (1996). Kinetics of the simultaneous utilization of sugar mixtures by Escherichia coli in continuous culture. Appl Environ Microbiol 62, 1493-1499.

Lohrke, S. M., Dery, P. D., Li, W., Reedy, R., Kobayashi, D. Y. \& Roberts, D. P. (2002). Mutation in rpiA in Enterobacter cloacae decreases seed and root colonization and biocontrol of damping-off caused by Pythium ultimum on cucumber. Mol Plant Microbe Interact $15,817-825$.

Lugtenberg, B. J. J., Kravchenko, L. V. \& Simons, M. (1999). Tomato seed and root exudate sugars: composition, utilization by Pseudomonas biocontrol strains and role in rhizosphere colonization. Environ Microbiol 1, 439-446.

Lugtenberg, B. J. J., Dekkers, L. \& Bloemberg, G. V. (2001). Molecular determinants of rhizosphere colonization by Pseudomonas. Annu Rev Plant Phytopathol 39, 461-490.

Lynch, A. S. \& Lin, E. C. (1996). Transcriptional control mediated by the ArcA two-component response regulator protein of Escherichia coli: characterization of DNA binding at target promoters. J Bacteriol 178, 6238-6249.
Lynch, J. M. \& Whipps, J. M. (1990). Substrate flow in the rhizosphere. Plant Soil 129, 1-10.

MacKenzie, S. L. (1987). Gas chromatographic analysis of amino acids as the $N$-heptafluorobutyryl isobutyl esters. J Assoc Off Anal Chem 70, 151-160.

Martínez-Granero, F., Capdevila, S., Sánchez-Contreras, M., Martín, M. \& Rivilla, R. (2005). Two site-specific recombinases are implicated in phenotypic variation and competitive rhizosphere colonization in Pseudomonas fluorescens. Microbiology 151, 975-983.

Mazzola, M., Cook, R. J., Thomashow, L. S., Weller, D. M. \& Pierson, L. S., III (1992). Contribution of phenazine antibiotic biosynthesis to the ecological competence of fluorescent pseudomonads in soil habitats. Appl Environ Microbiol 58, 2616-2624.

McDougall, B. M. \& Rovira, A. D. (1970). Sites of exudation of ${ }^{14} \mathrm{C}$ labeled compounds from wheat roots. New Phytol 69, 999-1003.

Meharg, A. A. (1994). A critical review of labeling techniques used to quantify rhizosphere carbon flow. Plant Soil 166, 55-62.

Melal, H. M. \& Sauerbeck, E. R. (1983). Method to study turnover processes in soil layers of different proximity to roots. Soil Biol Biochem 15, 223-225.

Meyer, S. L. F. \& Roberts, D. P. (2002). Combinations of biocontrol agents for management of plant-parasitic nematodes and soilborne plant-pathogenic fungi. J Nematol 34, 1-8.

Miller, J. H. (1972). Experiments in Molecular Genetics. Cold Spring Harbor, NY: Cold Spring Harbor Laboratory.

Nelson, E. B. (1988). Biological control of Pythium seed rot and preemergence damping-off of cotton with Enterobacter cloacae and Erwinia herbicola applied as seed treatments. Plant Dis 72, 140-142.

Owen, A. G. \& Jones, D. L. (2001). Competition for amino acids between wheat roots and rhizosphere microorganisms and the role of amino acids in plant $\mathrm{N}$ acquisition. Soil Biol Biochem 33, 651-657.

Park, S.-J., Chao, G. \& Gunsalus, R. P. (1997). Aerobic regulation of the sucABCD genes of Escherichia coli, which encode $\alpha$-ketoglutarate dehydrogenase and succinyl coenzyme A synthetase: roles of ArcA, Fnr, and the upstream $s d h C D A B$ promoter. J Bacteriol 179, 4138-4142.

Paulitz, T. C. (1990). Biochemical and ecological aspects of competition in biological control. In Alternatives for Suppressing Agricultural Pests and Diseases, pp. 713-724. Edited by R. R. Baker \& P. E. Dunn. New York: Alan R. Liss.

Peekhaus, N. \& Conway, T. (1998). What's for Dinner?: EntnerDoudoroff metabolism in Escherichia coli. J Bacteriol 180, 3495-3502.

Postma, J., Hok-A-Hin, C. H. \& Oude Voshaar, J. H. (1990). Influence of the inoculum density on the growth and survival of Rhizobium leguminosarum biovar trifolii introduced into sterile and non-sterile loamy sand and silt loam. FEMS Microbiol Ecol 73, 49-58.

Rainey, P. B. (1999). Adaptation of Pseudomonas fluorescens to the plant rhizosphere. Environ Microbiol 1, 243-257.

Roberts, D. P., Sheets, C. J. \& Hartung, J. S. (1992). Evidence for proliferation of Enterobacter cloacae on carbohydrates in cucumber and pea spermosphere. Can J Microbiol 38, 1128-1134.

Roberts, D. P., Marty, A. M., Dery, P. D., Yucel, I. \& Hartung, J. S. (1996). Amino acids as reduced carbon sources for Enterobacter cloacae during colonization of the spermospheres of crop plants. Soil Biol Biochem 28, 1015-1020.

Roberts, D. P., Dery, P. D., Hebbar, K. P., Mao, W. \& Lumsden, R. D. (1997a). Biological control of damping-off of cucumber caused by Pythium ultimum with a root-colonization-deficient strain of Escherichia coli. J Phytopathol 145, 383-388.

Roberts, D. P., Dery, P. D., Yucel, I., Buyer, J., Holtman, M. A. \& Kobayashi, D. Y. (1997b). Genetic analysis of the seed colonization 
mutant Enterobacter cloacae A-11. In Plant Growth-Promoting Rhizobacteria. Present Status and Future Prospects. Proceedings of the Fourth International Workshop on Plant Growth-Promoting Rhizobacteria, Japan-OECD Joint Workshop October 5-10, 1997, pp. 330-332. Edited by A. Ogashi, K. Kobayashi, Y. Homma, F. Kodama, N. Kondo \& S. Akino. Sapporo, Japan: Nakanishi Printing.

Roberts, D. P., Dery, P. D., Yucel, I., Buyer, J. S., Holtman, M. A. \& Kobayashi, D. Y. (1999). Role of $p f k A$ and general carbohydrate catabolism in seed colonization by Enterobacter cloacae. Appl Environ Microbiol 65, 2513-2519.

Roberts, D. P., Dery, P. D., Yucel, I. \& Buyer, J. S. (2000). Importance of $p f k A$ for rapid growth of Enterobacter cloacae during colonization of crop seeds. Appl Environ Microbiol 66, 87-91.

Roehl, R. A. \& Vinopal, R. T. (1976). Lack of glucose phosphotransferase function in phosphofructokinase mutants of Escherichia coli. J Bacteriol 126, 852-860.

Sambrook, J. \& Russell, D. W. (2001). Molecular Cloning. A Laboratory Manual. Cold Spring Harbor, NY: Cold Spring Harbor Laboratory.

Shen, J. \& Gunsalus, R. P. (1997). Role of multiple ArcA recognition sites in anaerobic regulation of succinate dehydrogenase $(s d h C D A B)$ gene expression in Escherichia coli. Mol Microbiol 26, 223-236.

Sørensen, J., Jensen, L. E. \& Nybroe, O. (2001). Soil and rhizosphere as habitats for Pseudomonas inoculants: new knowledge on distribution, activity and physiological state derived from micro-scale and single-cell studies. Plant Soil 232, 97-108.
Sullivan, J. E. \& Schewe, L. R. (1977). Preparation and gas chromatography of highly volatile trifluoroacetylated carbohydrates using $N$-methyl bis[trifluoroacetamide]. J Chromatog Sci 15, 196-197.

Toal, M. E., Yoemans, C., Killham, K. \& Meharg, A. A. (2000). A review of rhizosphere carbon flow modeling. Plant Soil 222, 263-281.

Veeger, C., DerVartanian, D. V. \& Zeylemaker, W. P. (1969). Succinate dehydrogenase [EC 1.3.99.1 succinate: (acceptor) oxidoreductase]. Methods Enzymol 13, 81-90.

Weller, D. M. (1988). Biological control of soilborne plant pathogens in the rhizosphere with bacteria. Annu Rev Phytopathol 26, 379-407.

Whipps, J. M. (1990). Carbon economy. In The Rhizosphere, pp. 5998. Edited by J. M. Lynch. New York: Wiley Interscience.

Wilson, M. \& Lindow, S. E. (1994). Inoculum density-dependent mortality and colonization of the phyllosphere by Pseudomonas syringae. Appl Environ Microbiol 60, 2232-2237.

Wood, D., Darlision, M. G., Wilde, R. J. \& Guest, J. R. (1984). Nucleotide sequence encoding the flavoprotein and hydrophobic subunits of the succinate dehydrogenase of Escherichia coli. Biochem J 222, 519-534.

Zhang, Z., Gosset, G., Barabote, R., Gonzalez, C. S., Cuevas, W. A. \& Saier, M. H. (2005). Functional interactions between the carbon and iron utilization regulators, Crp and Fur, in Escherichia coli. J Bacteriol 187, 980-990.

Edited by: M. F. Hynes 